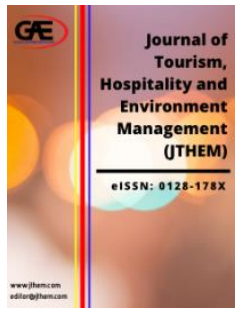

\author{
JOURNAL OF TOURISM, \\ HOSPITALITY AND \\ ENVIRONMENT MANAGEMENT \\ (JTHEM) \\ www.jthem.com
}

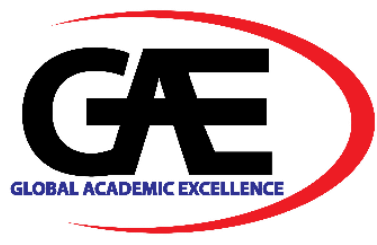

\title{
THE RELATIONSHIP BETWEEN COMPETITIVE INTELLIGENCE PROCESSES AND HOTELS' PERFORMANCE: EVIDENCE FROM MALAYSIA
}

\author{
Akram Mufareh Alshammakh ${ }^{1 *}$, Adi Anuar Azmin ${ }^{2}$
}

1 Faculty of Applied and Human Sciences, Universiti Malaysia Perlis, Malaysia, and Thamar University, Dhamar, Yemen

Email: alshamakha@yahoo.com

2 Faculty of Applied and Human Sciences, Universiti Malaysia Perlis, Malaysia

Email: adianuar@unimap.edu.my

Corresponding Author

\section{Article Info:}

\section{Article history:}

Received date: 15.09.2021

Revised date: 15.10 .2021

Accepted date: 26.10.2021

Published date: 01.12.2021

\section{To cite this document:}

Alshammakh, A. M., Azmin, A. A. (2021). The Relationship Between Competitive Intelligence Processes And Hotels' Performance: Evidence From Malaysia. Journal of Tourism Hospitality and Environment Management, 6 (26), 27-46.

DOI: $10.35631 /$ JTHEM.626002.

This work is licensed under $\underline{\mathrm{CC} B Y} 4.0$ (c)
Abstract:

Competitive intelligence (CI) is a proven systematic process used to improve an organization's competitiveness through the systematic collection, analysing, and communication of information to decision-makers. However, there is still ambiguity about the impact of each process of competitive intelligence process (CIPs) on performance, particularly in the hotel industry in a developing country like Malaysia. Thus, the purpose of this research is to detect the level of CIP practiced in Malaysian hotels, as well as to investigate the impact of each process from the CI processes (planning and focus, gathering, analysis, and communication) on the financial and non-financial performance of Malaysian hotels. A quantitative research design was adopted in this study. To obtain the necessary data for analysing the hypothesised model of the study, 505 questionnaires were issued to marketing managers in member hotels of the Malaysian Association of Hotels (MAH), and a total of 184 analysable questionnaires were gathered, with a response rate of $34.44 \%$. The research data were analysed using partial least squares structural equation modelling. Despite that half of the responding hotels practiced CI informally, and many of these hotels began practicing CI five years ago, the study found that the level of CIP practice was high. Furthermore, the results indicate that the planning and focus, gathering, and analysis processes of CIP had a positive and significant impact on hotels' performance, while the communication process had a negative but insignificant impact on hotels' performance. Additionally, the results show that the planning and focus process is the most relevant, followed by the analysis processes, and finally the gathering process. These findings enrich those in positions of power like owners, managers, and practitioners, as well as academicians, with greater knowledge of the 


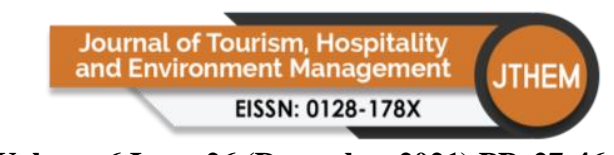

Volume 6 Issue 26 (December 2021) PP. 27-46

DOI 10/35631/JTHEM.626002

relationship and influence of CIPs on firms' performance, particularly for hospitality and tourism firms.

Keywords:

Hotel Performance. Competitive Intelligence Process. Hospitality. Tourism. Malaysia

\section{Introduction}

Tourism has become an important sector in many countries (Mohammed et al., 2017; Ahn \& Kwon, 2020). In Malaysia, the tourism industry is one of the key potential growth areas service economies, and it is the second-largest generator of foreign exchange in Malaysia (Yadegaridehkordi et al., 2020; Ahn \& Kwon, 2020). Where it created 3.4 million jobs in 2017 and contributed $15.2 \%$ to the Malaysian GDP in 2019, as well Malaysia welcomed 26.10 million tourists and generated RM 86.10 billion in 2019 (Tourism Malaysia, 2020). The hotel industry is one of the main components of tourism, and as such is one of the most promising sectors in Malaysia, where Malaysia offers a wide range of accommodation to visitors including hotels, individual guest houses, motels, self-catering, and other types of private accommodation, moreover, by the end of 2019, Malaysia had 4,826 hotels offering 315,969 rooms (Tourism Malaysia, 2020). Therefore, there is a need for efficient strategies to enable the Malaysian hotel industry to overcome the fierce competition (Mohammed et al., 2017; Yadegaridehkordi et al., 2018; Yadegaridehkordi et al., 2020; Ahn \& Kwon, 2020).

Despite the Malaysian government's focus on tourism, which was apparent through its 2020 vision to reach 36 million tourists, figures have revealed a decline from 27.44 million in 2014 to 26.10 million in 2019 in tourist arrivals in Malaysia (Yadegaridehkordi et al., 2020; Tourism Malaysia, 2020). Furthermore, prior researches have shown that the hotel sector works in an aggressive competitive environment and environmental turbulence, in resulting a dropped in the rate of occupancy, where the occupancy rate for Malaysian hotels fell between 2014 and 2019, starting at $69.7 \%$ in 2014 and falling to 58.8\% in 2019 (Mohammed et al., 2017; Radzi et al., 2017; Yadegaridehkordi et al., 2020; Tourism Malaysia, 2020). As a result, in order to stay competitive in such a difficult industry, hotel managers and executives should use appropriate strategic tools, such as Competitive Intelligence (CI), to help them stay in the market and flourish (Yap et al., 2014; Yan-Li \& He-feng, 2016; Salguero et al., 2019; Köseoglu et al., 2020).

Competitive intelligence (CI) systematic, targeted, timely and ethical process that focuses on collecting, synthesizing, and analysing information from both the internal and the external environment of the firm, and disseminate it to company decision-makers (Søilen, 2017; Calof et al., 2018; van den Berg et al., 2020; Oraee et al., 2020; Hanif et al., 2021). Furthermore, CI is a strategic instrument that aids in the identification of prospective opportunities and dangers (Du Toit 2015; Hendar et al., 2020; Oraee et al., 2020). Companies can use CI to improve their ability to access and evaluate competitive information, allowing them to better capture market opportunities (Søilen, 2017; Hendar et al., 2020; Silva, 2021). Companies can also utilise CI to increase their ability to obtain competitor information in a competitive setting and use that information for decision-making and performance improvement (Wright et al., 2009; Hendar et al., 2020; Calof \& Sewdass, 2020; Silva, 2021). Indeed, some researchers believe that CI is like a firm's radar to sense opportunities and threats surrounding (Søilen, 2017; Oraee et al., 


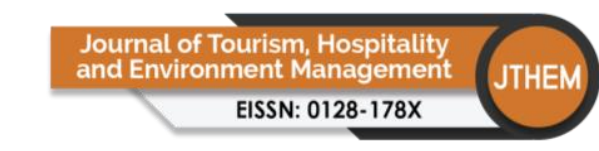

Volume 6 Issue 26 (December 2021) PP. 27-46 DOI 10/35631/JTHEM.626002

2020). As a result, CI is a valuable resource for strategic planning and other operations since it gives data on present and future rivals' activities (Hendar et al., 2020; Calof \& Sewdass, 2020; Silva, 2021). In this regard, CI has positioned itself among the top strategic practices for supporting an organization's performance and enhancing the competitive advantages of the organizations (Tej Adidam et al., 2012; Søilen, 2017; Maritz \& du Toit, 2018; Oraee et al., 2020; Falahat et al., 2020; Calof \& Sewdass, 2020; Vugec et al., 2020; Silva, 2021). Accordingly, CI is continuously emerging as a strategic practice for hotel companies to distinguish themselves from their competitors (Yap et al., 2014; Yan-li \& He-feng, 2015; Köseoglu et al., 2016; Yan-Li \& He-feng, 2016; Köseoglu et al., 2019; Salguero et al., 2019; Köseoglu et al., 2020). In addition, according to Yan-li \& He-feng (2015), Yan-Li and He-feng (2016), and Salguero et al. (2019), the hotel industry is in a dire need of CI especially in the era of big data where the better full practice of CI will assist hotel managers to develop well informed and wiser marketing decisions by providing them with quality, timely and overall information, which can, in turn, lead to competitive advantage and better performance for hotels.

Despite the imperative role of CI for organizational survival, the field of application has varied. Some companies use CI at the tactical level, while others use it at the strategic level, and there is also a disparity in the success of implementing CI from one company to another and from one sector to another (Yan-li \& He-feng, 2015; Köseoglu et al., 2016; Søilen, 2017; Cavallo et al., 2020; Silva, 2021). However, several studies have revealed that there is a low level of awareness of CI among hotel managers (Yap et al., 2014; Köseoglu et al., 2016; Köseoglu et al., 2019; Salguero et al., 2019; Köseoglu et al., 2020). Furthermore, although CI has been widely used in the service sector, the literature indicated limited research of CI within the hospitality sector (Köseoglu et al., 2016; Salguero et al., 2019; Köseoglu et al., 2020). Similarly, the impact of practicing the process of competitive intelligence (CIPs) as a multistage (Planning and focus, collection, analysis, and communication) on firm performance has not received enough attention from academics, and there is still a lack of empirical studies in this area (Tej Adidam et al., 2012; Yap et al., 2014; Du Toit 2015; Yap et al., 2018; Markovich et al., 2019; Sahin \& Bisson, 2021). Specifically, previous empirical studies which addressed CIPs in the Malaysian hotel context and tourism are still very scarce (Yap et al., 2014; Yap et al., 2018). Therefore, the use of firm performance (financial and non-financial performance) to evaluate the impact of CI processes in hotel companies is crucial (Yap et al., 2014; Yan-li \& He-feng, 2015; Yan-Li \& He-feng, 2016; Köseoglu et al., 2016; Köseoglu et al., 2019; Salguero et al., 2019; Köseoglu et al., 2020). Furthermore, these authors recommended that future studies should investigate CI dimensions in a variety of industries particularly the hotel industry. Thus, this study is one of the first to assess the influence of each process of CI on Malaysian hotels' financial and non-financial performance. Therefore, this study aims to fill this research gap by defining the level of CIP practiced in Malaysian hotels, as well as investigating the influence of each process of CIPs on the financial and non-financial performance of Malaysian hotels.

\section{Literature Review}

\section{Competitive Intelligence Processes (CIPs)}

Competitive intelligence is a well-established idea with a long history (Søilen, 2017; Oraee et al., 2020). According to Tao and Prescott (2000), Søilen (2017), and Oraee et al. (2020), CI dates back to around 5,000 years before Chinese history. Porter first proposed the concept of CI in 1980, when he published a paper on competitive strategy in academic circles (Oraee et 


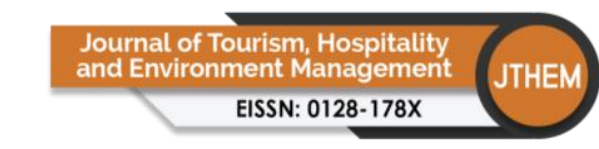

Volume 6 Issue 26 (December 2021) PP. 27-46 DOI 10/35631/JTHEM.626002

al., 2020). Moreover, the CI process seems to have expanded dramatically and is regarded as one of the most rapidly developing fields in the business domain due to $\mathrm{CI}$ involvement with various disciplines with different theoretical foundations such as management, economics, computer science, information science, etc (Oraee et al., 2020; Hanif et al., 2021). Also, the scientific associations and the professional community are active in this field (Søilen, 2017; Oraee et al., 2020). Despite that, Tao and Prescott (2000), Tej Adidam et al. (2012), Köseoglu et al. (2019), and Oraee et al. (2020), highlighted an important research gap on CI practice in emerging economies and stressed that not enough knowledge about how $\mathrm{CI}$ is conducted in these markets where the institutional framework differs greatly from that in the developed economies. Generally, no accurate and widely accepted CI definition is given, however various perspectives to define CI are found in the literature (Calof \& Wright 2008; Pellissier \& Nenzhelele, 2013; Oraee et al., 2020). According to Breakspear (2013), CI entails two concepts: competitiveness and intelligence. The former denotes a contest between two or more groups, organisations, or corporations. The latter refers to a corporate capability that incorporates foresight and insights, with the goal of recognising coming change, which could be positive in nature and represent opportunities, or negative in nature and represents threats (Breakspear, 2013). Furthermore, CI can be described as a process or a product, according to SCIP (2009), Yin (2018), and Oraee et al. (2020). The Society of Competitive Intelligence Professionals (SCIP) defines competitive intelligence (CI) as a continuous process that includes legal and ethical methods for gathering information, analysing it, and controlling its dissemination so that decision makers can make informed decisions about marketing, R\&D, and investing tactics, and long-term business strategies (SCIP, 2009). Meanwhile, as a product $\mathrm{CI}$ is described as information regarding current and future customer, competitor, and supplier behavior, as well as information on government, market, and general business environment (Yin, 2018). Therefore, the concept of CI was used as a process for the purposes of this study.

\section{Competitive Intelligence Processes (CIPs)}

is a continuous and integrated process with a set of phases that must be implemented in a specific sequential for generating competitive intelligence products (De Pelsmacker et al., 2005; Calof, 2017; Calof et al., 2018; Oraee et al., 2020). However, there is no agreement on which phases make up the CIP. As a result, CIP has been proposed in a variety of ways, and while there are certain similar features in each, there are still discrepancies in the structure of CIP, the number of phases, and the nomenclature for the various phases. Calof, 2017; Oraee et al., 2020). Despite that, there appears to be support for these stages of CIP ("Planning and focus, Collection, Analysis, and Communication") from previous studies (Saayman et al., 2008; Nasri, 2011; Seyyed-Amiri et al., 2017):

\section{Planning and Focus (CIP-PF) Phase:}

CIP-PF is concerned with defining decision-makers' needs, allocating necessary resources, and deciding on the goal and desired outcomes of CI. The significance of this phase is twofold: first, it is required to determine the necessary resources for the CI function; second, it allows CI practitioners to focus on what is most important for end-users (decision-makers) in terms of the required information for meeting or exceeding their demands and expectations (Saayman et al., 2008; Nasri, 2011; Pellissier \& Nenzhelele, 2013; Seyyed-Amiri et al., 2017; Oraee et al., 2020). 


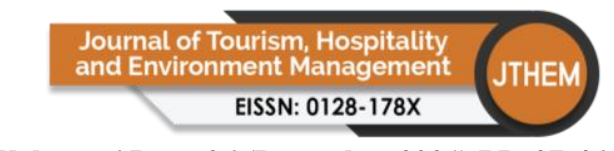

Volume 6 Issue 26 (December 2021) PP. 27-46 DOI 10/35631/JTHEM.626002

\section{The Gathering Phase (CIP-G):}

CIP-G is concerned with identifying potential sources of information and collecting data or information legally and ethically by utilising various sources, including internal and external, qualitative and quantitative, human sources, and textual (Saayman et al., 2008; Nasri, 2011; Pellissier \& Nenzhelele, 2013; Seyyed-Amiri et al., 2017; Oraee et al., 2020). It is also important to note that collection also entails ensuring that the potential sources and information are accurate (Calof, et. al, 2018; Lutz \& Bodendorf, 2020; Hanif et al., 2021).

\section{The Analysis Phase (CIP-A):}

CIP-A is an important part of the CI process because it is here that actual intelligence is formed (Pellissier \& Nenzhelele, 2013; Calof, et. al, 2018). It is primarily concerned with converting acquired data into actionable intelligence on which tactical and strategic decisions are based (Calof et. al, 2018; Hanif et al., 2021). The analysis phase examines the collected and relevant data and information for applicability and significance, then transforms the results into actionable intelligence that will improve the planning and decision-making process, ultimately leading to the development of essential strategies and improve performance (Salguero et al., 2017; Oraee et al., 2020). Furthermore, based on the literature, there are a number of techniques for analysis that may be used to provide the intelligence needed to make strategic decisions, where, these techniques were Boston Consulting Group (BCG growth) or the share portfolio matrix, industry analysis (Porter's Five Forces Model), The General Electric Business Screen matrix, strategic group analysis, financial ratios, SWOT analysis (Strengths, Weaknesses, Opportunities, Threats) and value chain analysis (Nasri, 2011; Salguero et al., 2017; Oraee et al., 2020; Lutz \& Bodendorf, 2020).

\section{The Communication Phase (CIP-C):}

CIP-C is an important stage of CIP because it ensures that the findings of the analysis phase (intelligence process) are properly communicated to decision-makers who are authorised and responsible to act on the findings in a format that is easily understood, using various channels such as e-mails, reports, seminars, short notes, and so on (Saayman et al., 2008; Nasri,2011; Salguero et al., 2017; Calof, et. al, 2018; Hanif et al., 2021). The communication phase, moreover, provides input that can help improve the CI process, particularly between the intelligence team and decision-makers (Nasri, 2011; Salguero et al., 2017; Hanif et al., 2021).

\section{Hotel's Performance}

Hotel performance is interested in the final outcomes of hotel process activities $(\mathrm{Wu} \& \mathrm{Lu}$, 2012; Mohammed et al., 2017; Cheangtawee et al., 2020). The present dynamic and complicated business environment made the performance measurement one of the most important elements for organizations (Mohammed et al., 2017; Wamba et al., 2019; Falahat et al., 2020). Thus, recently, many scholars and researchers remarkable demonstrated attention on the issue of performance measurement and management (Mohammed et al., 2017; Yap et al., 2018; Wamba et al., 2019; Falahat et al., 2020; Vugec et al., 2020; Sahin \& Bisson, 2021). Thus, evaluating performance using a comprehensive measure that takes into account all aspects of a company's operations is critical in assisting an organisation in managing its resources and effectively controlling its goals (Wu \& Lu, 2012; Mohammed et al., 2017; Cheangtawee et al., 2020). This scale is a financial and non-financial performance measure (Kaplan \& Norton, 1992). The financial and non-financial performance measurement was used by Wu and Lu (2012), Mohammed et al. (2017), and Cheangtawee et al. (2020) to assess hotel performance. This measure considers four aspects of corporate performance: financial, 


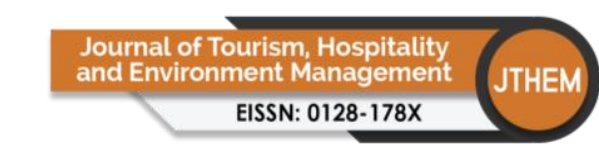

Volume 6 Issue 26 (December 2021) PP. 27-46 DOI 10/35631/JTHEM.626002

customer, internal process, and learning and growth (Mohammed et al., 2017). Integrating these four views, according to Kaplan and Norton (1992), can help managers better comprehend cross-functional interactions in their organisations, leading to better problem solving and decision making. In this regard, Tej Adidam et al. (2012) and Yap et al. (2018) said that financial measures can't provide a whole picture of CI influence, thus the total performance view should be used to assess CI outcomes. As a result, using a financial and non-financial performance measure to examine the impact of CIPs ("planning and focus, gathering, analysis, and communication") on hotel performance is conclusive because it is a useful measure for evaluating an organization's overall operational (Wu \& Lu, 2012; Mohammed et al., 2017; Cheangtawee et al., 2020). Finally, using a financial and non-financial performance measure to monitor company performance on both non-financial and financial metrics gives firms a holistic view of their operations. As a result, the four elements of performance measure (customer, financial, internal process, and learning and growth) are used to reflect and measure hotel performance in this study.

\section{Hypotheses Development}

\section{CIPs and Hotel's Performance}

$\mathrm{CI}$ is part of the BI that works as a strategic tool to identify opportunities and potential threats (Du Toit 2015; Hendar et al., 2020). Additionally, based on previous empirical studies in CI, $\mathrm{CI}$ is a multi-dimensional construct that involves two dimensions which are Competitive Intelligence Process (CIP) and Competitive Intelligence Context (CIC) (Calof \& Dishman, 2002; Saayman et al., 2008; Seyyed-Amiri et al., 2017). Furthermore, the literature on CI noted that the very essence of CI lies in its ability to improve decision making, and to support decision makers to make informed decisions, which can, in turn, lead to competitive advantage and better firm performance (Mohamad et al., 2018; Markovich et al., 2019; Salguero et al., 2019; Lutz \& Bodendorf, 2020; Hanif et al., 2021). According to Oraee et al. (2020) and Calof and Sewdass (2020), CIP improves business performance by a continuous and integrated process with a set of phases that must be implemented in a specific sequential for generating competitive intelligence products. Where a company's aims and business goals can be met or exceeded with the help of CIP (Yin, 2018; Salguero et al., 2019; Kumar et al., 2020; Oraee et al., 2020). Other researchers highlighted that CIP helps managers stay up with the fast-paced changes and growing competition (Köseoglu et al., 2016; Mohamad et al., 2018). According to Tej Adidam et al. (2012), the Indian firms that exhibit higher levels of CIPs have attained better financial performance results. Furthermore, Seyyed-Amiri et al. (2017) investigated the relationship between CIP (as a group), and the competitive advantage of Iranian insurance companies, and found that the CIP has a positive relationship to competitive advantage. Similarly, Yin (2018) found that CI as (process and product) have a significant effect on organizational performances. CIP enables businesses to learn more about themselves and their competitors, to enhance their decision-making and strategy development, and, most importantly, to increase their productivity and efficiency, resulting in higher performance (Mohamad et al., 2018). In a fast-growing and constantly changing industry like the hotel industry, organisations operating in many clusters of industry require CIP to grow and survive (Köseoglu et al., 2016; Salguero et al., 2017; Salguero et al., 2019). Therefore, we proposed the following hypotheses:

H1: The CIP's planning and focus phase influences hotels' performance in Malaysia.

H2: The CIP's gathering phase influences hotels' performance in Malaysia. 


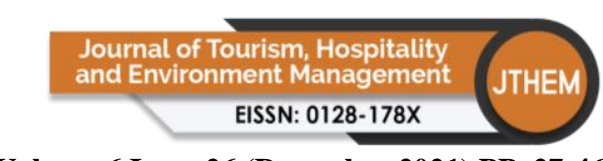

Volume 6 Issue 26 (December 2021) PP. 27-46

DOI 10/35631/JTHEM.626002

H3: The CIP's analysis phase influences hotels' performance in Malaysia.

H4: The CIP's communication phase influences hotels' performance in Malaysia.

According to the theoretical framework and prior hypotheses, the conceptual framework will be depicted as in Fig.1.

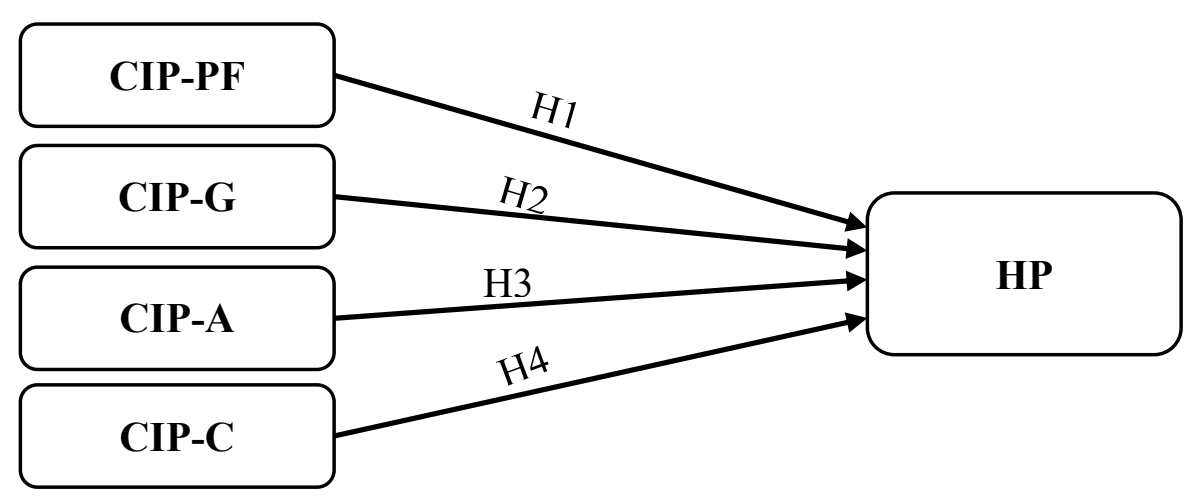

Figure1: The Conceptual Framework

\section{Methodology}

The main goal of this research is to define the level of CIP practiced in Malaysian hotels, as well as investigating the influence of each process of CIPs on the financial and non-financial performance of Malaysian hotels. To achieve these goals, we employed a quantitative approach to collect data from Malaysian hotels' marketing managers. There is empirical evidence from previous studies where researchers in previous studies used hotel marketing managers as the main respondents e.g., Yap et al. (2014), Yan-li \& He-feng (2015), Yan-Li and He-feng (2016), Köseoglu et al. (2016) and Köseoglu et al. (2019), moreover, Yap et al. (2014), Köseoglu et al. (2019) and Markovich et al. (2019) noted that CI unit is located within the marketing management. Thus, it is anticipated that the marketing managers will be accurate to fully answer virtually all questions. The population in this study comprised hotels in Malaysia with 3- to 5-star ratings, which totalled 535 hotels in December 2018, according to the Malaysian Association of Hotels (MAH, 2018). Yap et al. (2014) and Köseoglu et al. (2016) argued that these types of hotels are suitable for investigating CIP since they are superior to one-star and two-star hotels in terms of management organisation, information handling, and institutionalisation. Because of the study population's small size, Zikmund (2003) and Zikmund et al. (2013) advised that if the population has a small population size, the researcher should investigate the entire population rather than selecting a sample size. Thus, we used a survey of the total population, which included 535 -3 to 5-star hotels based on the MAH membership database. Since Malaysian hotels are located in various and spaced areas, data was gathered using a questionnaire over a four-month period from November 2019 to February 2020. After excluding the 30 hotels that were used in the pilot study, the questionnaires were distributed via email to the marketing managers of 505 hotels. Due to the low recovery rate of email surveys, researchers visited hotels in Northern Malaysia (Pulau Pinang, Kedah, and Perlis), as well as the majority of hotels in Kuala Lumpur, Selangor, and Malacca, and the total number of questionnaires recovered is 192. After checking for damaged questionnaires and outlier data, the final review of the questionnaires received yielded 184 questionnaires (36.44 percent) that were appropriate for data analysis. In terms of the profile of respondents, the male respondents made up 45.1 percent of the total, while female respondents made up 54.9 percent. The majority 


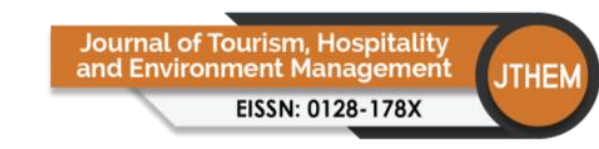

Volume 6 Issue 26 (December 2021) PP. 27-46 DOI 10/35631/JTHEM.626002

of the responders were between the ages of 36 and 45 with $44.6 \%$. All respondents held a managerial role, with the majority $(91.3 \%)$ holding the marketing manager job, followed by the sales manager position (7.6\%). As a result, all respondents were regarded qualified to answer questions on the hotel's performance and CIP practice. They were also aware of CI practices, as the majority of respondents had worked in this hotel for 4-9 years and had a percentage of 68 percent, while the majority of the respondents had ten years and more of experience working in the hotel sector, with a percentage of 67.4 percent. In terms of hotel profile, 31.5 percent of hotels were classified as "three-star," 40.2 percent as "four-star," and the rest as "five-star". The majority of the hotels, on the other hand, were classified as city hotels (78.8 percent). 75 percent of hotels have been open for more than ten years, making them mature establishments. The majority of these hotels had over 300 rooms. In addition, Selangor had the highest percentage of people who responded to the survey, with 26.6 percent.

\section{Measures}

CIP measure was adopted from Saayman et al. (2008) and Seyyed-Amiri et al. (2017), which was adjusted for the survey of the hotel industry in Malaysia. Where CIP has been measured by 18 items divided into four sub-dimensions are (planning and focus (CIP-PF) have 4 items, gathering (CIP-G) has 4 items, analysis (CIP-A) has 6 items, and communication (CIP-C) has 4 items). Furthermore, hotel's performance (HP) has been measured by the four elements of financial and non-financial performance, where the customer perspective (HP-CP) has 4 items, financial (HP-FP) has 5 items, internal process (HP-IPP) has 4 items, and learning and growth (HP-LGP) has 4 items) were drawn from Kaplan and Norton (1992), which were refined by Mohammed et al. (2017), where it included 17 items. Previous research has found that subjective assessments of CIPs and HP can be useful. The five constructs were assessed using a "5-point Likert scale, with 1 indicating "strongly disagree" and 5 indicating "strongly agree" for the statements proposed". After that, respondents were asked to give their opinions on CIPs and HP in their hotels over the previous three years.

\section{Results}

To analyse the results of this study and to achieve its objectives, two statistical packages were used, namely, the statistical package for social sciences "SPSS" and "structural equation modelling for partial least squares". Where the first package was used to measure the nature and level of CIP use in Malaysian hotels. While we used SEM-PLS to evaluate the measurement model and structural model in order to report key findings on the "measurement model" and the "structural model" which include constructing, the validity of discriminant and convergent, the analysis of reliability, and the predictive importance for the model. The path modelling of PLS had successfully expanded use in several research fields, like, strategicmanagement, marketing, information-system, social psychology, and management science than others (Hair et al., 2019). According to Hair et al. (2019) PLS-SEM considers a suitable and sturdy method to numerous situations observed in the research of social-sciences.

\section{The Nature and Level of CIP Use in Malaysian Hotels}

As shown in the table.1, descriptive statistics of frequencies and percentages were calculated in relation to the nature of CIP use in Malaysian hotels. According to table.1. 51.1 percent of Malaysian hotels use CIP as an informal, while 48.9 percent use it as a formal. Meanwhile, 74.5 percent of hotels reported that the CIP was located in Marketing/Market research Management, while 13.6 percent reported that the CIP in their hotels has a separate department. Furthermore, 58.7 percent of hotels began establishing CIP in less than 5 years, while 37.5 
Volume 6 Issue 26 (December 2021) PP. 27-46

DOI 10/35631/JTHEM.626002

percent of hotels began establishing CIP in 5-10 years. In addition, 56 percent of hotels have 1 to 5 employees involved in CIP activities, while 21.7 percent have 6 to 10 employees involved in CIP activities.

\begin{tabular}{cccc} 
Table 1: Descriptive Statistics of The Nature of CIP use in Malaysian Hotels & N=184) \\
\hline Variable & Description & F & \% \\
\hline Using CI & Yes & 184 & 100 \\
Type of using & No & 0 & 0.0 \\
CIP & Formal & 90 & 48.9 \\
& Informal & 94 & 51.1 \\
& Market/Marketing research & 137 & 74.5 \\
& Corporate planning & 8 & 4.3 \\
& The Finance & 5 & 2.7 \\
CIP unit Location & Research \& development & 5 & 2.7 \\
& Information Technology & 2 & 1.1 \\
& A separate department & 25 & 13.6 \\
& Others & 2 & 1.1 \\
& lesser than-5 years & 108 & 58.7 \\
Years of CIP unit & 5-10-Years & 69 & 37.5 \\
established & 11-15-Years & 2 & 1.1 \\
& 16-Years and More & 5 & 2.7 \\
Number of & 1-5-Employee & 103 & 56.0 \\
employees & 6-10-Employee & 40 & 21.7 \\
involved in CIP & 11-15-Employee & 21 & 11.4 \\
activities & more than 15-employee & 2 & 1.1 \\
& No dedicated set of employees & 18 & 9.8 \\
\hline
\end{tabular}

In order to measure the level of practicing the CIPs (planning and focus (CIP-PF), gathering (CIP-G), analysis (CIP-A), and communication (CIP-C)) in Malaysian hotels, descriptive statistics were calculated that include mean and deviations' standards. As explained above, structures were measured in the current study using the "5-point Likert scale". So, we used three classes depending on Noor and Kumar (2014), to illustrate the level of practicing the CIPs in Malaysian hotels, namely: the low values which are less than 2.33 ("4/3 + lowest-value (1)"), the high values which are higher than 3.67 (the highest-value "(5) - 4/3)" and the moderate values which are located among high and low values.

Furthermore, the overall mean for all processes of the CIP ranged between, 3.88 to 3.95, which indicated that all the processes get the high level of mean values, as well the total mean value of CIP had a high level of mean with 3.92 value, as displayed in table 2. In specific, all processes of CIP (CIP-PF, CIP-G, CIP-A, and CIP-C) have the high level of the mean 3.90, $3.95,3.95$, and 3.88 with low standard deviation $0.69,0.69,66$, and 0.65 respectively, this reflects the interest of marketing managers in Malaysian hotels on the importance of processes of CIP and its impact of hotel's performance. The high level of mean values reflects that the level of CIP practice is high in Malaysian hotels. see Table. 2. 
Table 2. Descriptive Statistics of the CIPs (N=184)

\begin{tabular}{ccccc}
\hline \multirow{2}{*}{ Construct } & Item & Mean & $\begin{array}{c}\text { Std. } \\
\text { Deviation }\end{array}$ & $\begin{array}{c}\text { Level of } \\
\text { practice }\end{array}$ \\
\hline \multirow{4}{*}{ Planning and } & CIP_PF1 & 4.34 & 0.74 & High \\
Focus (CIP-PF) & CIP_PF2 & 3.68 & 0.77 & High \\
& CIP_PF3 & 3.88 & 0.79 & High \\
& CIP_PF4 & 3.68 & 0.99 & High \\
& Total & $\mathbf{3 . 9 0}$ & $\mathbf{0 . 6 9}$ & High \\
\hline \multirow{5}{*}{ Gathering (CIP-G) } & CIP_G1 & 4.08 & 0.87 & High \\
& CIP_G2 & 3.69 & 0.77 & High \\
& CIP_G3 & 4.10 & 0.75 & High \\
& CIP_G4 & 3.92 & 0.91 & High \\
& Total & $\mathbf{3 . 9 5}$ & $\mathbf{0 . 6 9}$ & High \\
\hline \multirow{5}{*}{ Analysis (CIP-A) } & CIP_A1 & 3.94 & 0.82 & High \\
& CIP_A2 & 3.97 & 0.81 & High \\
& CIP_A3 & 4.18 & 0.81 & High \\
& CIP_A4 & 4.07 & 0.83 & High \\
& CIP_A5 & 3.91 & 0.71 & High \\
& CIP_A6 & 3.63 & 0.92 & High \\
& Total & $\mathbf{3 . 9 5}$ & $\mathbf{0 . 6 6}$ & High \\
\hline Total of CIP practices & $\mathbf{3 . 9 2}$ & $\mathbf{0 . 6 3}$ & High \\
\hline & CIP_C1 & 3.82 & 0.85 & High \\
Communication & CIP_C2 & 4.03 & 0.72 & High \\
& CIP_C3 & 3.52 & 0.74 & Moderate \\
& CIP_C4 & 4.15 & 0.80 & High \\
& Total & $\mathbf{3 . 8 8}$ & $\mathbf{0 . 6 5}$ & High \\
\hline \multirow{5}{*}{ CIP-C) } & & & \\
& & & \\
& & &
\end{tabular}

\section{The Resulting of The Measurement Model}

This study used the guidelines published by Hair et al. (2019) to evaluate the measurement model, looking at construct, convergent, and discriminant validity. When a test is designed, construct validity refers to the application of the results obtained by applying the measure and appropriate theories (Sekaran \& Bougie, 2016). This concept can be realised by looking at the item's factor loading in the measurement model's content validity (Chin, 2010; Hair et al., 2014). All items should be significantly higher on their hypothesised factor than on other factors in this situation (Chin, 2010). As a result, if some objects load other factors higher than their respective build, they are destroyed (Hair et al., 2014). As a major factor, this paper uses factor loading with a cut-off criterion of 0.7. (Hair et al., 2019). Table 3 shows that the loadings for all items were greater than 0.70 . Therefore, this finding confirms the content validity of the measurement model. As a result, this conclusion supports the measurement model's content validity.

The construct being measured can be estimated using factor loadings, composite reliability (CR), and the extracted average variance (AVE). The recommended loading is set at 0.70; CR must be greater than 0.70 , and AVE should be greater than the generally accepted cut-off point 
Volume 6 Issue 26 (December 2021) PP. 27-46

DOI 10/35631/JTHEM.626002

of 0.50. Using item loadings, the item loading for the hypothesized factor was found to be significantly higher than the other components (Chin, 2010). Furthermore, CR findings were higher than outcomes that were over 0.70. The AVE indicates that the latent variable was greater than 0.50 (Hair et al., 2019). The findings in Table 3 are higher than predicted levels, thereby validating the convergent validity of the measuring model.

Table 3: Load Factor and Convergent Validity Findings

\begin{tabular}{|c|c|c|c|c|}
\hline $\begin{array}{c}\text { Model } \\
\text { Construct }\end{array}$ & $\begin{array}{l}\text { Measurement } \\
\text { Item }\end{array}$ & Loading & $\begin{array}{l}\text { Composite } \\
\text { Reliability } \\
\text { (CR) }\end{array}$ & $\begin{array}{c}\text { Average } \\
\text { Variance } \\
\text { Extracted } \\
\text { (AVE) }\end{array}$ \\
\hline \multirow{4}{*}{$\begin{array}{l}\text { Planning and } \\
\text { Focus (CIP-PF) }\end{array}$} & CIP_PF1 & 0.828 & \multirow{4}{*}{0.907} & \multirow{4}{*}{0.711} \\
\hline & CIP_PF2 & 0.895 & & \\
\hline & CIP_PF3 & 0.842 & & \\
\hline & CIP_PF4 & 0.804 & & \\
\hline \multirow{3}{*}{$\begin{array}{l}\text { Gathering } \\
\text { (CIP-G) }\end{array}$} & CIP_G1 & 0.868 & \multirow{3}{*}{0.897} & \multirow{3}{*}{0.745} \\
\hline & CIP_G2 & 0.848 & & \\
\hline & CIP_G3 & 0.872 & & \\
\hline \multirow{5}{*}{$\begin{array}{c}\text { Analysis (CIP- } \\
\text { A) }\end{array}$} & CIP_A1 & 0.865 & \multirow{5}{*}{0.916} & \multirow{5}{*}{0.688} \\
\hline & CIP_A2 & 0.896 & & \\
\hline & CIP_A3 & 0.888 & & \\
\hline & CIP_A4 & 0.746 & & \\
\hline & CIP_A5 & 0.735 & & \\
\hline \multirow{3}{*}{$\begin{array}{l}\text { Communication } \\
\text { (CIP-C) }\end{array}$} & CIP_C1 & 0.891 & \multirow{3}{*}{0.939} & \multirow{3}{*}{0.837} \\
\hline & CIP_C2 & 0.933 & & \\
\hline & CIP_C4 & 0.920 & & \\
\hline \multirow{4}{*}{$\begin{array}{c}\text { Customer } \\
\text { perspective } \\
(\mathrm{HP}-\mathrm{CP})\end{array}$} & HP_CP1 & 0.898 & \multirow{4}{*}{0.929} & \multirow{4}{*}{0.766} \\
\hline & HP_CP2 & 0.930 & & \\
\hline & HP_CP3 & 0.807 & & \\
\hline & HP_CP4 & 0.859 & & \\
\hline \multirow{5}{*}{$\begin{array}{c}\text { Financial } \\
\text { perspective } \\
(\text { HP-FP) }\end{array}$} & HP_FP1 & 0.814 & \multirow{5}{*}{0.923} & \multirow{5}{*}{0.706} \\
\hline & HP_FP2 & 0.791 & & \\
\hline & HP_FP3 & 0.790 & & \\
\hline & HP_FP4 & 0.899 & & \\
\hline & HP_FP5 & 0.898 & & \\
\hline \multirow{4}{*}{$\begin{array}{l}\text { Internal process } \\
\text { perspective } \\
\text { (HP-IPP) }\end{array}$} & HP_IPP1 & 0.826 & \multirow{4}{*}{0.936} & \multirow{4}{*}{0.786} \\
\hline & HP_IPP2 & 0.839 & & \\
\hline & HP_IPP3 & 0.942 & & \\
\hline & HP_IPP4 & 0.933 & & \\
\hline \multirow{4}{*}{$\begin{array}{l}\text { Learning and } \\
\text { growth } \\
\text { perspective } \\
\text { (HP-LGP) }\end{array}$} & HP_LGP1 & 0.835 & \multirow{4}{*}{0.902} & \multirow{4}{*}{0.698} \\
\hline & HP_LGP2 & 0.826 & & \\
\hline & HP_LGP3 & 0.851 & & \\
\hline & HP_LGP4 & 0.829 & & \\
\hline
\end{tabular}


After the convergent-validity was confirmed, we ran the Fornell and Larcker (1981) technique to examine the discriminant validity. To what extent is a group of items used to estimate only one construct, and to what extent is the separate estimation of this construct accomplished in the process (Hair et al., 2014). The correlation between the latent constructs will need to be greater than the square root of the AVE of each latent construct to successfully implement this approach (Hair et al., 2014; Fornell and Larcker, 1981). It can be concluded that discriminant validity is fully established because the square root of the AVE values exceeded in their own rows and columns after deleted 2 items (CIP-A6 and CIP-G4). Table 4. displays the findings, and fig 2. display the measurement model.

Table 4: Results of Discriminant Validity by "Fornell-Larcker Criterion"

\begin{tabular}{ccccccccc}
\hline Construct & $\begin{array}{c}\text { CIP- } \\
\mathbf{A}\end{array}$ & $\begin{array}{c}\text { CIP- } \\
\text { C }\end{array}$ & $\begin{array}{c}\text { CIP- } \\
\text { G }\end{array}$ & $\begin{array}{c}\text { CIP- } \\
\text { PF }\end{array}$ & $\begin{array}{c}\text { HP- } \\
\text { CP }\end{array}$ & $\begin{array}{c}\text { HP- } \\
\text { FP }\end{array}$ & $\begin{array}{c}\text { HP- } \\
\text { IPP }\end{array}$ & $\begin{array}{c}\text { HP- } \\
\text { LGP }\end{array}$ \\
\hline CIP-A & $\mathbf{0 . 8 3 0}$ & & & & & & & \\
CIP-C & 0.828 & $\mathbf{0 . 9 1 5}$ & & & & & & \\
CIP-G & 0.823 & 0.762 & $\mathbf{0 . 8 6 3}$ & & & & & \\
CIP-PF & 0.815 & 0.716 & 0.826 & $\mathbf{0 . 8 4 3}$ & & & & \\
HP-CP & 0.653 & 0.532 & 0.680 & 0.721 & $\mathbf{0 . 8 7 5}$ & & & \\
HP-FP & 0.661 & 0.501 & 0.666 & 0.661 & 0.732 & $\mathbf{0 . 8 4 0}$ & & \\
HP-IPP & 0.709 & 0.626 & 0.717 & 0.720 & 0.847 & 0.743 & $\mathbf{0 . 8 8 7}$ & \\
HP-LGP & 0.755 & 0.656 & 0.746 & 0.735 & 0.648 & 0.606 & 0.791 & $\mathbf{0 . 8 3 5}$ \\
\hline & & & & & & & &
\end{tabular}

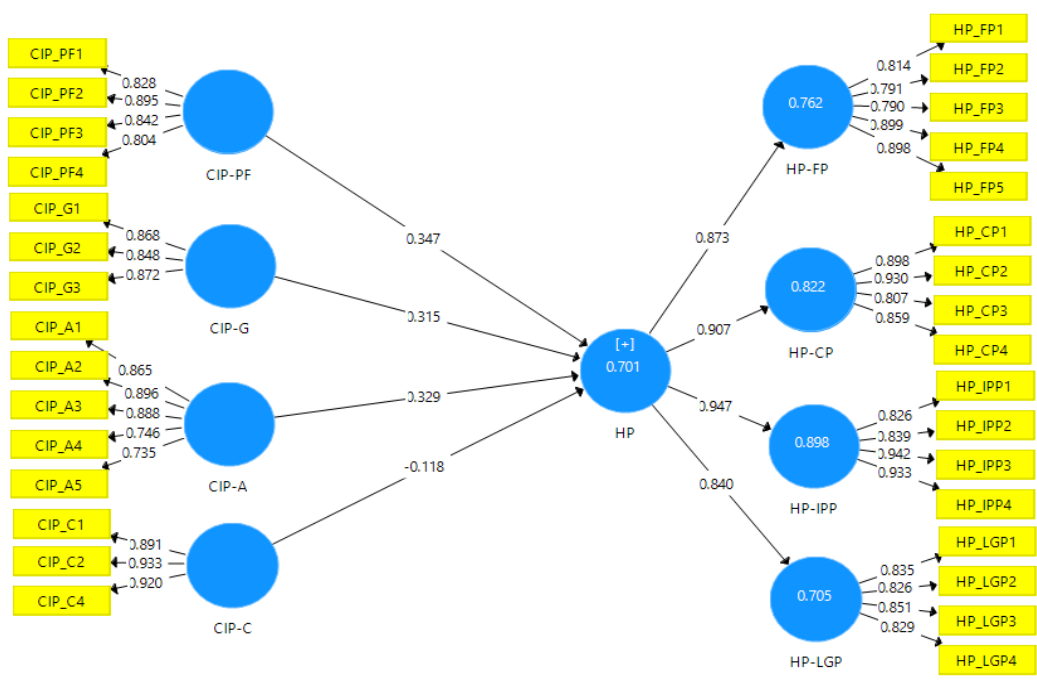

Figure 2: Measurement Model and Path-Coefficient Results 


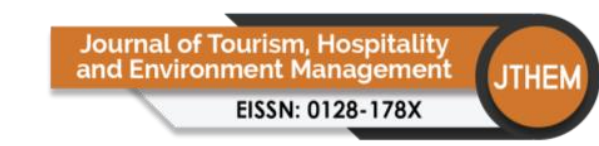

Volume 6 Issue 26 (December 2021) PP. 27-46

DOI 10/35631/JTHEM.626002

According to the findings, the recommended conceptualization of CIP-PF, CIP-G, CIP-A, and CIP-C of CIP as reflecting first-order structures was supported. This methodology is in agreement with prior research that has combined ECIP-PF, CIP-G, CIP-A, and CIP-C to create a unified approach (Saayman et al., 2008; Seyyed-Amiri et al., 2017; Hanif et al., 2021). To identify and explain the whole performance of firms, the many dimensions construct (as second-order structures) were utilized instead of a single construct (HP-CP, HP-FP, HP-IPP, and HP-LGP) used in the studies of Kaplan and Norton (1992) and Mohammed et al. (2017) in this study. This research seeks to learn more about the correlation between CIP-PF, CIP-G, CIP-A, and CIP-C so that we can enhance our comprehension of how they are related to other variables.

\section{Structure-mode Valuation}

Once the model's validity and reliability had been confirmed, the hypothesized link was investigated using Smart-PLS 3.3.3. Figures $2 \& 3$, and Table 5 illustrate the results. Hair et al. (2014) noted that the important criterion for the structural model evaluation is R2, as the predictive PLS-SEM approach tries to illuminate the variance of the endogenous latent variables. So, R2, which is one of the primary objectives, should be placed in a high position. They also considered the $\mathrm{R}^{2}$ value of $0.75,0.50$, and 0.25 , and arrived at the conclusion that these values were "high, moderate, and weak", respectively. In our study, $\mathrm{R}^{2}$ obtained a value of 0.701 using the PLS algorithm, and this value is almost at a high level. Figure 2 shows that the CIP-PF, CIP-G, CIP-A, and CIP-C approaches account for $70.1 \%$ of the variation in hotels' performance, which is in the high range. using the blindfolding approach, the model was also assessed to see if it was of a high enough quality (Henseler et al., 2015). The Stone-Geisser test can be used to simulate soft modelling comparable to hand in glove, says Valerie (2012). "This test is computed through the formula $\mathrm{Q}^{2}=1-$ sum of squares of prediction errors (SSE)/sum of squares of observations (SSO)". When blindfolding is employed, the value of $\mathrm{Q}^{2}$ is derived by counting the number of cases in the data instead of the given omissions distance. If the value of $\mathrm{Q}^{2}$ is not a multiple of the given omissions distance, then the blindfolding method provides inaccurate values, and values from 5 to 10 should be used (Hair et al., 2014). Since this research utilised 9 as the value of $d$ to represent the cross-validated redundancy methods for each dependent variable, the current research selected 7 as the value of d. According to Hair et al. (2014), if the cross-redundancy value is larger than zero, the model has predictive value; otherwise, one cannot make any conclusions about the predictive relevance of the model. The cross-validated redundancy of hotels' performance was 0.404 , as shown in Table 6 . Thus, it was concluded that the model's prediction quality is satisfactory.

\begin{tabular}{cccccc}
\multicolumn{6}{c}{ Table 5: Hypothesis-Testing Results } \\
\hline Hypotheses & $\begin{array}{c}\text { Path } \\
\text { coefficient }\end{array}$ & $\begin{array}{c}\text { Standard } \\
\text { error }\end{array}$ & $\begin{array}{c}\text { T } \\
\text { Statistics }\end{array}$ & $\begin{array}{c}\text { P- } \\
\text { Values }\end{array}$ & Results \\
\hline CIP-PF -> HP & 0.347 & 0.090 & 3.850 & 0.000 & Supported \\
CIP-G -> HP & 0.315 & 0.077 & 4.118 & 0.000 & Supported \\
CIP-A -> HP & 0.329 & 0.081 & 4.087 & 0.000 & Supported \\
CIP-C -> HP & -0.118 & 0.079 & 1.489 & 0.137 & Not \\
Supported
\end{tabular}

Note: $* * *: p<0.01 ; * *: p<0.05 ; *: p<0.1$. 
Table 6: Model's Prediction Relevance

\begin{tabular}{cccc}
\hline Total & SSO & SSE & $\begin{array}{c}\mathrm{Q}^{2}(=1- \\
\text { SSE/SSO })\end{array}$ \\
\hline Hotel's Performance & 3128.000 & 1857.600 & 0.406 \\
\hline
\end{tabular}

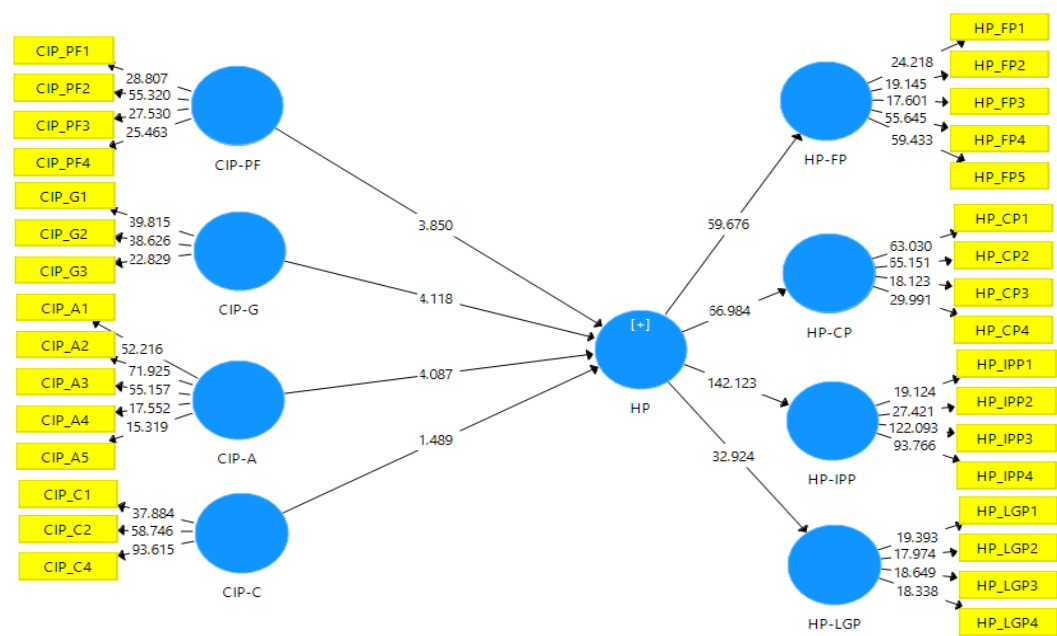

Figure 3: Hypothesis-Testing Results

\section{Discussion and Implications}

The hospitality industry is in desperate need of CI, particularly in the age of big data, where better CI practises would assist hotel managers in making better marketing decisions based on the quality of information, timely, and comprehensive data, resulting in a competitive advantage and improved hotel performance (Yan-li \& He-feng, 2015; Yan-Li \& He-feng, 2016; Salguero et al., 2019). As a result, the current study sought to ascertain the nature and extent of CI practise in hotels in an emerging economy such as Malaysia. Furthermore, the study seeks to determine the impact of each process of CIPs on hotel performance. To achieve the first goal, descriptive statistics were used, as it was discovered that half of the studied hotels practise $\mathrm{CI}$ informally, at a rate of 51 percent, and that the majority of Malaysian hotels began practising CI five years ago, at a rate of 58.7 percent, while 37.5 percent began practising CI ten years ago. The marketing department, on the other hand, was found to be the most interested in CI, with a percentage of 74.5 percent. Furthermore, 56 percent of hotels have one to five employees working for CI. On the other hand, the level of CIPs practise for each CIP's process (planning and focus (CIP-PF), gathering (CIP-G), analysis (CIP-A), and communication (CIP-C)) operation in Malaysian hotels, was high, with the arithmetic means for each operation reaching $(3.90,3.95,3.95$, and 3.88) respectively, and all these values are considered high based on Noor and Kumar (2014). This demonstrates that marketing managers in Malaysian hotels place a high value on each process of CIPs. Although marketing managers place a high value on each of the CIP's operations, the CI practise in Malaysian hotels is still in its infancy and requires the attention of hotel executives to encourage the establishment of formal CI practise units.

The second objective of this study is to examine the effect of CIPs (planning and focus (CIP$\mathrm{PF}$ ), gathering (CIP-G), analysis (CIP-A), and communication (CIP-C)) on Malaysian hotels' performance, which is the important processes of CIPs practices (Saayman et al., 2008; Tej Adidam et al., 2012; Seyyed-Amiri et al., 2017; Oraee et al., 2020). The empirical result reveals 


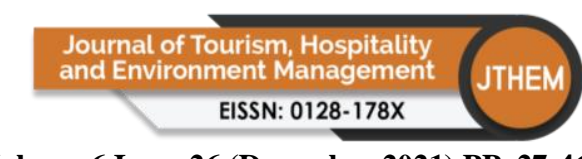

Volume 6 Issue 26 (December 2021) PP. 27-46 DOI 10/35631/JTHEM.626002

that the CIP-PF has an impact on hotel performance $(\beta=0.347, t=3.850, p<0.001)$, as shown in Table 5. As a result, $\mathrm{H} 1$ is acceptable. This conclusion is since hotels that practise planning and focus (CIP-PF) inside CIPs are defined by defining decision-makers' needs, allocating appropriate resources, and deciding on the CIP's purpose and desired outcomes. This phase is crucial for two reasons: first, it is essential to determine the required resources for the CI function, and second, it allows CI practitioners to focus on what is most relevant to end-users (Saayman et al., 2008; Seyyed-Amiri et al., 2017; Oraee et al., 2020). As a result, hotels that use CIP-PF achieve better performance.

The second part of the second objective of this study is to examine the effect of gathering (CIPG) on Malaysian hotels' performance, which is one of the important processes of CIPs practices (Tej Adidam et al., 2012; Seyyed-Amiri et al., 2017; Oraee et al., 2020). The empirical result reveals that the CIP-G has an impact on hotel performance $(\beta=0.315, t=4.118, p<0.001)$, as shown in Table 5. As a result, $\mathrm{H} 2$ is acceptable. This conclusion is based on the fact that hotels that practise gathering (CIP-G) inside CIPs are concerned with identifying potential sources of information and collecting data or information legally and ethically by utilising various sources, including internal and external, qualitative and quantitative, human sources, and textual, and It is also important to note that collection also entails ensuring that the potential sources and information are accurate (Saayman et al., 2008; Nasri, 2011; Seyyed-Amiri et al., 2017; Oraee et al., 2020). As a result, hotels that use CIP-G achieve better results.

The third part of the second objective of the study is to examine the effect of analysis (CIP-A) on Malaysian hotels' performance, which is one of the important processes of CIPs practices, because in this process that actual intelligence is formed (Saayman et al., 2008; Pellissier \& Nenzhelele, 2013; Calof, et. al, 2018). The empirical result reveals that the CIP-A has an impact on hotel performance $(\beta=0.329, \mathrm{t}=4.087, \mathrm{p}<0.001)$, as shown in Table 5. As a result, $\mathrm{H} 3$ is acceptable. This conclusion is based on the fact that hotels that practise analysis (CIP-A) inside CIPs concerned with the collected and relevant data and information for applicability and significance, then transforms the results into actionable intelligence that will improve the planning and decision-making process, ultimately leading to the development of essential strategies and improve performance (Salguero et al., 2017; Oraee et al., 2020; Hanif et al., 2021). As a result, hotels that use CIP-A achieve better results.

The fourth part of the second objective of the study is to examine the effect of communication (CIP-C) on Malaysian hotels' performance, which is one of the important processes of CIPs practices, because it ensures that the findings of the analysis phase (intelligence process) are properly communicated to decision-makers who are authorised and responsible to act on the findings in a format that is easily understood, using various channels such as e-mails, reports, seminars, short notes, and so on (Saayman et al., 2008; Pellissier \& Nenzhelele, 2013; Calof, et. al, 2018). The empirical result reveals that the CIP-C has a negative impact on hotel performance, but its not significant $(\beta=-0.118, \mathrm{t}=1.489, \mathrm{p}>0.05)$, as shown in Table 5. As a result, $\mathrm{H} 4$ is inacceptable. In this case, the researchers have concluded that this outcome can be attributed to the fact that many of the hotels surveyed were practicing CIP informally. Therefore, hotels should strive to establish a formal CI unit, and train CI staff in communication tools to communicate the results of the CIP to decision makers according to their needs.

In general, the results of this study proved that all stages of CIP affect the performance of hotels by $70 \%$, that is, the CIP-PF, CIP-G, CIP-A, and CIP-C approaches account for $70.1 \%$ of the 


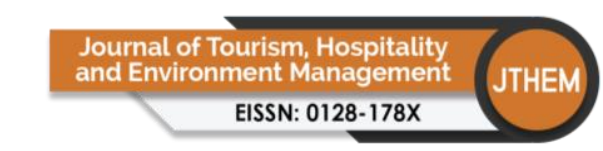

Volume 6 Issue 26 (December 2021) PP. 27-46 DOI 10/35631/JTHEM.626002

variation in hotels' performance, which is in the high range. This result is in line with the previous studies examining the firm performance such as Tej Adidam et al. (2012), SyyedAmiri et al. (2017), Yin (2018) and Salguero et al. (2019). Although this result confirms the significant effect of CIP on firms' performance, there is limited research in the hotel sector such as Yan-Li and He-feng (2015) and Yan-Li and He-feng (2016).

\section{Conclusion and Limitations}

This study is one of the first studies that look at the effect of practice (CIP-PF, CIP-G, CIP-A, and CIP-C) on hotels' performance in Malaysia. The researchers also conducted an additional investigation about the level of CIPs practice in Malaysian hotels. The findings from the study showed that the CIP-PF, CIP-G, and CIP-A processes were strongly linked to shotels' performance. Additional evidence shows that the CIP-PF process is the most relevant, followed by the CIP-A process, and finally the CIP-G process. While the CIP-C process does not have a significant impact on hotels' performance. Moreover, the results showed that although half of the Malaysian hotels were practicing CI informally, the level of CIPs practice was at a high level for all processes of CIPs. These findings have major implications for understanding how hotels improve their performance. The observed difference in the shift from survival mode to hotels' growth is most clearly demonstrated by a combination of the three processes.

This study contains limitations such as the challenge of obtaining all the hotels located in every state of Malaysia, as well as the effect of the Corona pandemic, which kept researchers from gathering additional data. Also, this study looked into the relationship between the hotels' performance in the Malaysian setting and the several CIPs (CIP-PF, CIP-G, CIP-A, and CIPC). This allows future studies to concentrate on investigating new dimensions of CI, with an increase in the response rate. The second flaw is that the existing research is limited to the hospitality industry. Future studies should therefore concentrate on the other industry in Malaysia. The third consideration is that this investigation is being done in Malaysia. Thus, In order to generalise the findings, future studies can replicate the findings in different nations.

\section{References}

Ahn, J., \& Kwon, J. (2020). Green hotel brands in Malaysia: perceived value, cost, anticipated emotion, and revisit intention. Current Issues in Tourism, 23(12), 1559-1574.

Breakspear, A., 2013. A new definition of intelligence. Intelligence National Security, 28 (5), 678-693.

Calof, J. (2017). Canadian competitive intelligence practices-a study of practicing strategic and competitive intelligence professionals Canadian members. Foresight, 19(6), 577589.

Calof, J. L., \& Wright, S. (2008). Competitive intelligence: A practitioner, academic and interdisciplinary perspective. European Journal of Marketing, 42(7/8), 717-730.

Calof, J., \& Sewdass, N. (2020). On the relationship between competitive intelligence and innovation. Journal of Intelligence Studies in Business, 10(2), 32-43.

Calof, J., Arcos, R., \& Sewdass, N. (2018). Competitive intelligence practices of European firms. Technology Analysis \& Strategic Management, 30(6), 658-671.

Cavallo, A., Sanasi, S., Ghezzi, A., \& Rangone, A. (2020). Competitive intelligence and strategy formulation: connecting the dots. Competitiveness Review: An International Business Journal, 31: 250-75.

Cheangtawee, P., Paopun, N., \& Fongsuwan, W. (2020). The Development of Key Performance Indicators for E-Commerce in Hotel Businesses Using Balanced 


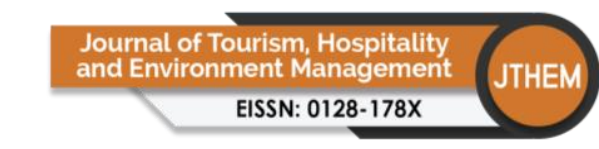

Volume 6 Issue 26 (December 2021) PP. 27-46

DOI 10/35631/JTHEM.626002

Scorecard. Proceedings of the Fourth International Conference on eBusiness, November (19-20), Bangkok, Thailand.

Chin, W. W. (2010). How to write up and report PLS analyses. In: Vinzi, V.E., Chin, W. W., Henseler, J. \& Wang, H. (Eds.), Handbook of Partial Least Squares, first ed. Springer, Berlin, pp. 655-690.

De Pelsmacker, P., Muller, M. L., Viviers, W., Saayman, A., Cuyvers, L., \& Jegers, M. (2005). Competitive intelligence practices of South African and Belgian exporters. Marketing Intelligence \& Planning, 23(6), 606-620.

Du Toit, A. S. (2015). Competitive intelligence research: An investigation of trends in the literature. Journal of Intelligence Studies in Business, 5(2), 14-21.

Falahat, M., Ramayah, T., Soto-Acosta, P., \& Lee, Y. Y. (2020). SMEs internationalization: The role of product innovation, market intelligence, pricing and marketing communication capabilities as drivers of SMEs' international performance. Technological Forecasting and Social Change, 152, 1-7.

Fornell, C. \& Larcker, D. (1981). Evaluating structural equation models with unobservable variables and measurement error. Journal of Marketing Research, 18(1), 39-50.

Hair, J. F., Hult, G. T. M., Ringle, C. M., \& Sarstedt, M. (2014). A primer on partial least squares structural equation modeling (PLS-SEM). Thousand Oaks: Sage Publications. Retrieved from http://www.sagepub.com/books/Book237345

Hair, J. F., Risher, J. J., Sarstedt, M., \& Ringle, C. M. (2019). When to use and how to report the results of PLS-SEM. European Business Review, 31(1), 2-24.

Hanif, N., Arshed, N., \& Farid, H. (2021) Competitive intelligence process and strategic performance of banking sector in Pakistan. J. Business Information Systems, 1-24.

Hendar, H., Ratnawati, A., Ab Razak, W. M. W., \& Abdullah, Z. (2020). Market intelligence on business performance: The mediating role of specialized marketing capabilities. Journal of Intelligence Studies in Business, 1(1), 42-58.

Henseler, J., Ringle, C. M., \& Sarstedt, M. (2015). A new criterion for assessing discriminant validity in variance-based structural equation modeling. Journal of the academy of marketing science, 43(1), 115-135.

Kaplan, R. S., \& Norton, D. P. (1992). The balanced scorecardMeasures that drive performance. Harvard Business Review, 70(1), 71-79.

Köseoglu, M. A., Mehraliyev, F., Altin, M., \& Okumus, F. (2020). Competitor intelligence and analysis (CIA) model and online reviews: integrating big data text mining with network analysis for strategic analysis. Tourism Review, DOI: 10.1108/TR-102019-0406.

Köseoglu, M. A., Morvillo, A., Altin, M., De Martino, M., \& Okumus, F. (2019). Competitive intelligence in hospitality and tourism: a perspective article. Tourism Review, 28, 690710.

Köseoglu, M. A., Ross, G., \& Okumus, F. (2016). Competitive intelligence practices in hotels. International Journal of Hospitality Management, 53 (-), 161-172.

Kumar, V., Saboo, A. R., Agarwal, A., \& Kumar, B. (2020). Generating competitive intelligence with limited information: a case of the multimedia industry. Production and Operations Management, 29(1), 192-213.

Lutz, C. J., \& Bodendorf, F. (2020). Analyzing industry stakeholders using open-source competitive intelligence-a case study in the automotive supply industry. Journal of Enterprise Information Management, 33(3), 579-599. 
MAH, Malaysia, 31 December,

2018.

Available

from: http://www.hotels.org.my/directories.html.

Maritz, R., \& du Toit, A. (2018). The practice turn within strategy: Competitive intelligence as integrating practice. South African Journal of Economic and Management Sciences, 21(1), 1-14.

Markovich, A., Efrat, K., Raban, D. R., \& Souchon, A. L. (2019). Competitive intelligence embeddedness: Drivers and performance consequences. European Management Journal, (-), 1-11.

Mohamad, N. H., Shabani, M., \& Woods, P. C. (2018). Competitive Intelligence Awareness in Creative Multimedia Industry in Malaysia. Advanced Science Letters, 24(2), 10221026.

Mohammed, A. A., Rashid, B. B., \& Tahir, S. B. (2017). Customer relationship management and hotel performance: the mediating influence of marketing capabilities-evidence from the Malaysian hotel industry. Information Technology \& Tourism, 17(3), 335361.

Nasri, W. (2011). Competitive intelligence in Tunisian companies. Journal of Enterprise Information Management, 24(1), 53-67.

Noor, N. A. M., \& Kumar, D. (2014). ECO friendly 'activities' VS ECO friendly 'attitude': Travelers intention to choose green hotels in Malaysia. World Applied Sciences Journal, 30(4), 506-513.

Oraee, N., Sanatjoo, A., \& Ahanchian, M. R. (2020). The competitive intelligence diamond model with the approach to standing on the shoulders of giants. Library \& Information Science Research, 42(2), 1-12.

Pellissier, R., \& Nenzhelele, T. E. (2013). Towards a universal competitive intelligence process model. South African Journal of Information Management, 15(2), 1-7.

Radzi, S. M., Yasin, M. F. M., Zahari, M. S. M., Ahmat, N. H. C., \& Ong, M. H. A. (2017). Moderating Effects of Environmental Variables on the Relationship Between BOS and Performance of Four and Five Star Hotels in Kuala Lumpur, Selangor, and Putrajaya, Malaysia. Advanced Science Letters, 23(11), 10830-10833.

Saayman, A., Pienaar, J., de Pelsmacker, P.J., Viviers, W., Cuyvers, L., Muller, M.-L., \& Jegers, M. (2008). Competitive Intelligence: Construct exploration, validation and equivalence. Aslib Proceedings: New Information Perspectives, 60(4), 383-411.

Sahin, M., \& Bisson, C. (2021). A competitive intelligence practices typology in an airline company in Turkey. Journal of the Knowledge Economy, 12(2), 899-922.

Salguero, G. C., Gámez, M. Á. F., Fernández, I. A., \& Palomo, D. R. (2019). Competitive Intelligence and Sustainable Competitive Advantage in the Hotel Industry. Sustainability, 11(6), 1-12.

Salguero, G. C., Resende Jr, P. C., \& Fernández, I. A. (2017). Proposal of an assessment scale in competitive intelligence applied to the tourism sector. Journal of Intelligence Studies in Business, 7(2), 38-47.

SCIP (2009). Social Citizenship Indicator Program database homepage. Available at Available at https://dspace.it.su.se/dspace/handle/10102/7. (last accessed 18 January 2009)

Sekaran, U. and Bougie, R. (2016), Research Methods for Business: A Skill Building Approach, John Wiley \& Sons, Queensland.

Seyyed-Amiri, N. A. D. E. R., Shirkavand, S., Chalak, M., \& Rezaeei, N. (2017). Competitive intelligence and developing sustainable competitive advantage. AD-Minister, 30(-), 173-194. 


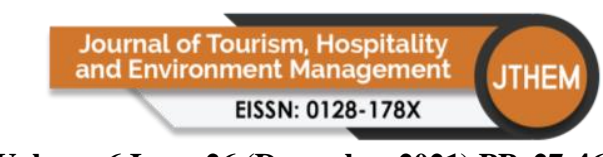

Volume 6 Issue 26 (December 2021) PP. 27-46

DOI 10/35631/JTHEM.626002

Silva, P. M. (2021). Examination in B2B trade show: the effects of competitive intelligence and the information management system on the exhibitor's marketing strategy. Journal of Marketing Analytics, 1-14.

Søilen, K. S. (2017). Why care about competitive intelligence and market intelligence? The case of Ericsson and the Swedish Cellulose Company. Journal of Intelligence Studies in Business, 7(2), 27-39.

Sun, L., \& Wang, Y. Z. (2015). Identifying the core competitive intelligence based on enterprise strategic factors. Journal of Shanghai Jiaotong University (Science), 20(1), 118-123.

Tao, Q., \& Prescott, J. E. (2000). China: Competitive intelligence practices in an emerging market environment. Competitive Intelligence Review, 11(4), 65-78.

Tej Adidam, P., Banerjee, M., \& Shukla, P. (2012). Competitive intelligence and firm's performance in emerging markets: an exploratory study in India. Journal of Business \& Industrial Marketing, 27(3), 242-254.

Tourism Malaysia (2020) Tourism Malaysia-statistics. Retrieved 10 Jul 2020 from: https://www.tourism.gov.my/statistics.

Valerie, F. (2012). Re-discovering the PLS approach in management science. M@n@gement,15(1), 101-123.

van den Berg, L., Coetzee, B., \& Mearns, M. (2020). Establishing competitive intelligence process elements in sport performance analysis and coaching: A comparative systematic literature review. International Journal of Information Management, 52, 102071.

Vugec, D. S., Vukšić, V. B., Bach, M. P., Jaklič, J., \& Štemberger, M. I. (2020). Business intelligence and organizational performance. Business Process Management Journal, DOI 10.1108/BPMJ-08-2019-0342.

Wamba, S. F., Akter, S., Trinchera, L., \& De Bourmont, M. (2019). Turning information quality into firm performance in the big data economy. Management Decision, 57(8), 1756-1783.

Wright, S., Eid, E. R., \& Fleisher, C. S. (2009). Competitive intelligence in practice: empirical evidence from the UK retail banking sector. Journal of Marketing Management, 25(910), 941-964.

Wu, S. I., \& Lu, C. L. (2012). The relationship between CRM, RM, and business performance: A study of the hotel industry in Taiwan. International Journal of Hospitality Management, 31(1), 276-285.

Yadegaridehkordi, E., Nilashi, M., Nasir, M. H. N. B. M., \& Ibrahim, O. (2018). Predicting determinants of hotel success and development using Structural Equation Modelling (SEM)-ANFIS method. Tourism Management, 66, (-), 364-386.

Yadegaridehkordi, E., Nilashi, M., Shuib, L., Nasir, M. H. N. B. M., Asadi, S., Samad, S., \& Awang, N. F. (2020). The impact of big data on firm performance in hotel industry. Electronic Commerce Research and Applications, (40), 1-33.

Yan-Li, B., \& He-feng, H. (2016, October). Framework and management of competitive intelligence system for tourist hotels in the era of big data. In Computer and Communications (ICCC), 2016 2nd IEEE International Conference on (pp. 60-64). IEEE, Oct. 14-17, 2016, Chengdu, China, 60-64.

Yan-Li, B., \& He-feng, H. (2015, December). Research on evaluation index system of tourist hotels' competitive intelligence ability. In Computer Science and Network Technology (ICCSNT), 2015 4th International Conference on (Vol. 1, pp. 495-499). IEEE, December 19-20, 2015, Harbin, China. 
Volume 6 Issue 26 (December 2021) PP. 27-46 DOI 10/35631/JTHEM.626002

Yap, C. S., Cheng, B. L., \& Choe, K. L. (2014). Web 2.0 as a tool for market intelligence acquisition in the Malaysian hotel industry. Information Research, 19(4), 55-70

Yap, C. S., Cheng, B. L., Mohamad Hussain, N., \& Ahmad, R. (2018). Innovativeness, market intelligence practices, and firm performance of small-and medium-sized tour operators. Tourism and Hospitality Research, 18(2), 143-151.

Yin, C. Y. (2018). Measuring organizational impacts by integrating competitive intelligence into executive information system. Journal of Intelligent Manufacturing, 29(3), 533547.

Zikmund, W. G. (2003). Sample designs and sampling procedures. Business Research Methods, 7(2), 368-400.

Zikmund, W. G., Babin, B. J., Carr, J. C., \& Griffin, M. (2013). Business research methods (9th edition). SOUTH-WESTERN, USA: Cengage Learning. 